\title{
ACTIVE POWER FILTER USING ADAPTIVE FILTERS IN THE SYNCHRONOUS FRAME REFERENCE
}

\author{
FABIO E. ROJAS R ${ }^{1}$, CÉSAR L. TRUJILLO R $^{2} \&$ EDWIN RIVAS T ${ }^{3}$ \\ ${ }^{1,2}$ Grupo de Investigación en Sistemas Eléctricos y Eficiencia Energética, Ingeniería Eléctrica, Universidad Distrital Francisco \\ José de Caldas-Bogotá, Colombia
}

${ }^{3}$ Grupo de Investigación en Compatibilidad Electromagnética, Ingeniería Eléctrica, Universidad Distrital Francisco José de Caldas, Bogotá, Colombia

\begin{abstract}
This paper introduces an implementation of an active power filter employing an adaptive filter in the synchronous frame reference (SFR) for harmonic current mitigation in low voltage systems. The target of this filter is to reduce the harmonic current content in systems where can exist variations of the fundamental frequency. Further, the control design in the SFR gives the opportunity not only to mitigate harmonic current but also to compensate reactive power and regulate voltage under linear and nonlinear loads. Experimental results on a $1 \mathrm{~kW}$ prototype are provided to show the feasibility of the proposed control strategy. Finally, the conclusions are presented.
\end{abstract}

KEYWORDS: Active power filter (APF), adaptive filter, LMS algorithm, current loop,voltage source inverter VSI

Received: Nov 08, 2020; Accepted: Nov 28, 2020; Published: Dec 04, 2020; Paper Id.: IJMPERDDEC20203

\section{INTRODUCTION}

Nowadays, technological advances and population growth have led to the need for more and more efficient sources of electrical energy that can supply the demand with high-quality standards. The quality of the electric power has been an issue that is becoming important in the electric sector, this is due to changes in the types of loads (increase in nonlinear loads and the use of loads sensitive to changes in parameters in the electricity grid), in addition to the massive use of renewable energy sources (solar, wind, geothermal, among others). These changes have generated negative impacts on low and medium voltage grids, resulting in possible instability of the electrical system, an increase of technical losses and reduction of the life of some equipment (conductors, transformers, switches, fuses, etc.) [1]. One of the most important aspects to consider when talking about the quality of electrical power is the subject of harmonics. Harmonics are signals of different frequency and magnitude that are related to a fundamental signal. This fundamental signal, in the electric case, can be of voltage or current, with current harmonics being the most important since their presence produces the greatest number of negative impacts on the electrical grid [2].

To mitigate these negative impacts on the electrical power system, it was necessary to use equipment capable of reducing the harmonic content of the current. Initially, the use of circuits with passive components such as resistances, inductors, and capacitors, were the most common solution since they provide a simple and inexpensive solution. However, these kings of passive filters altered the topology of the grid where they were installed, and brigs additional problems such as the change in impedance and resonance associated with frequency variations [3]. As a feasible solution, emerge the use of filters with active components, which depending on their control configuration, can mitigate the harmonic content of the grid, as well as compensate reactive power and balance the voltages and 
currents of the electrical grid [4], [5].

This paper presents the design and implementation of an APF based on a Voltage Source Inverter (VSI). The proposed approach starting from the modeling and control design of the active power filter. The model is represented in the $D Q$ synchronous reference frame which allows an easy tuning of the inner current control loops [ref inner]. The referent current signal with harmonic content used for the APF is obtained utilizing an adaptive filter using the Least Mean Squared (LMS) algorithm which reduces the harmonic content supplied by the main grid with less time response in comparison with conventional filters [6]. Finally, the proposed strategy has been tested experimentally and the results are presented together with the conclusions in the last section.

\section{MODELING AND CONTROL OF THE ACTIVE POWER FILTER}

Figure 1 shows the typical connection of an APF in parallel with the ac grid. This APF is a three-phase voltage source inverter based on IGBTs which is connected through a line inductor to the point of common coupling of the load with the ac power grid. For the dc side, a stiff dc bus has been assumed to simplify the design of the controllers.

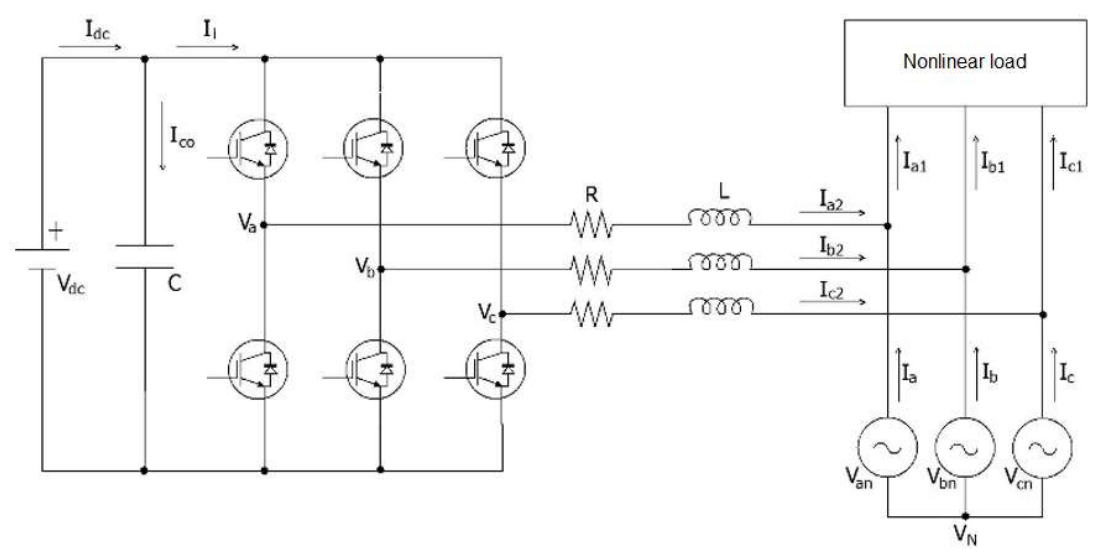

Figure 1: Typical connection of APF

\subsection{Averaged Model}

Each one of the branches of the VSI can be modeled as a simple switch using the model of the PWM switch [7]. This model is based on the duty cycle given as a result of the average values of voltage and current, generated by the commutation of the upper and lower IGBT of each branch.

Figure 2 shows the equivalent circuit for a single branch, where $d_{\varnothing}(\varnothing=a, b, c)$ represent each one of the duty cycles in which the upper switch of the branches a, b, and c are closed in each branch respectively. Whereas $\overline{V_{\varnothing}}$ and $\overline{I_{\varnothing}}$ denote the average values of the voltage and current.

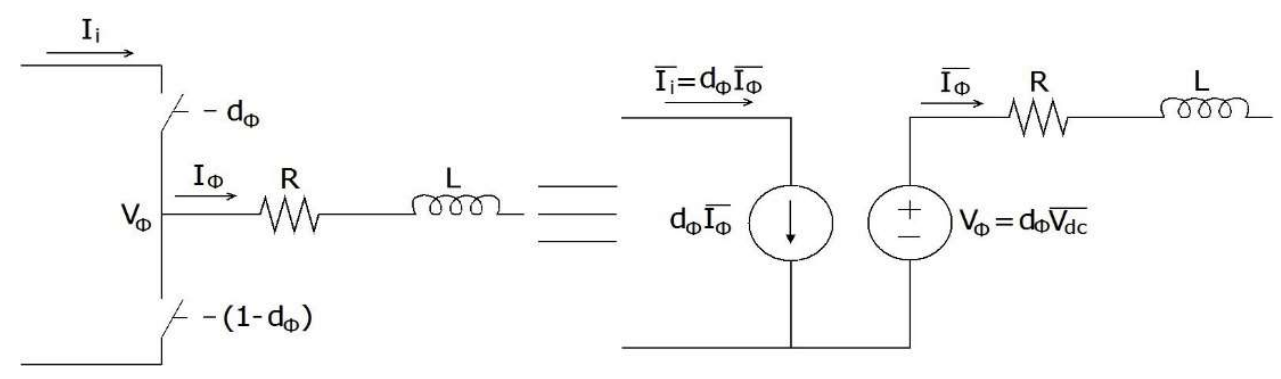

Figure 2: The average equivalent circuit for a single branch 
Figure 3 shows a complete model that includes all the branches of the three-phase VSI connected to the power system. From Figure 3 it is possible to derive the equation (1) which represents the model of the system in the stationary reference frame as.

$$
\frac{d}{d t}\left[\begin{array}{l}
\overline{I_{a 2}} \\
\overline{I_{b 2}} \\
\overline{I_{c 2}}
\end{array}\right]=\frac{\overline{V_{D C}}}{L}\left[\begin{array}{l}
d_{a} \\
d_{b} \\
d_{c}
\end{array}\right]-\frac{R}{L}\left[\begin{array}{l}
\overline{I_{a 2}} \\
\overline{I_{b 2}} \\
\overline{I_{c 2}}
\end{array}\right]-\frac{1}{L}\left[\begin{array}{l}
\overline{V_{a n}} \\
\overline{V_{b n}} \\
\overline{V_{c n}}
\end{array}\right]-\frac{V_{N}}{L}\left[\begin{array}{l}
1 \\
1 \\
1
\end{array}\right] \text { (1) }
$$

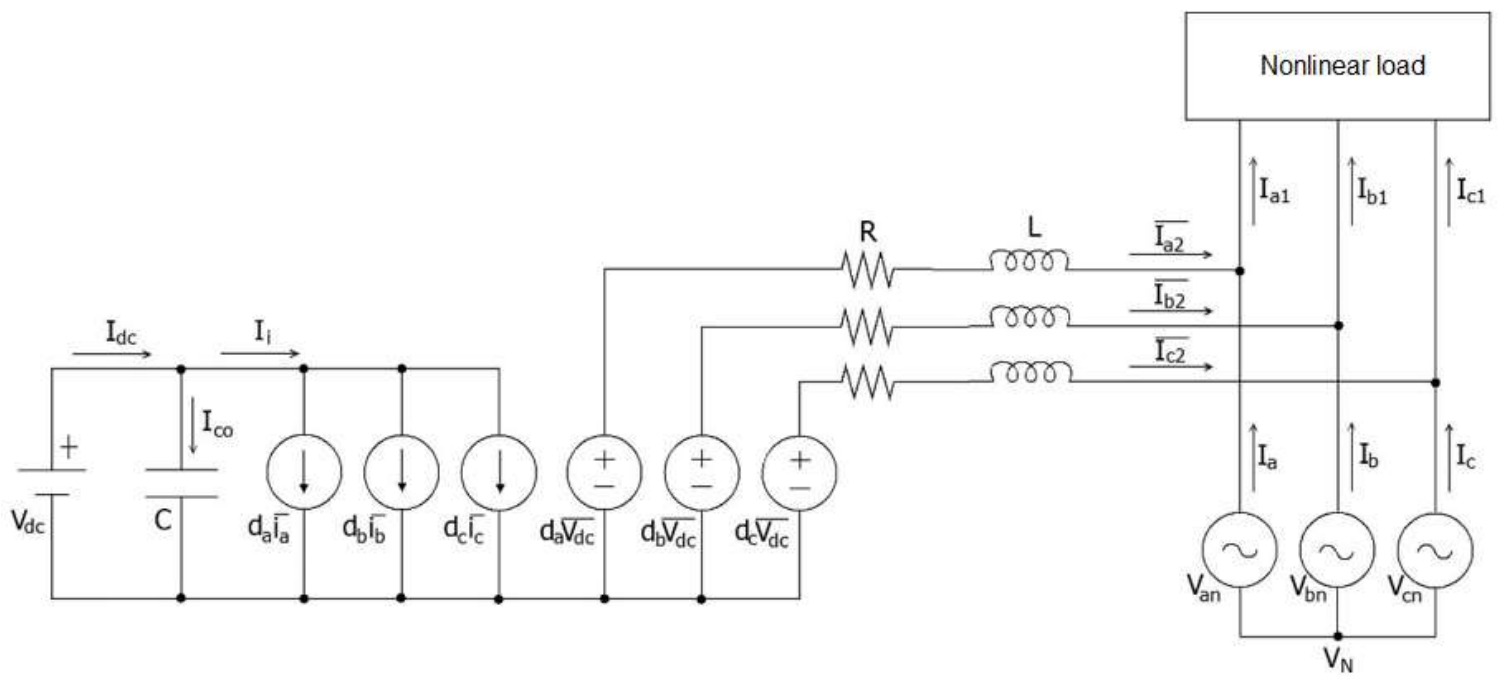

Figure 3: Average equivalent circuit of the three-phase system in the stationary reference frame

By applying Clark-Park transformation [8], [9], equation (1) can be rewritten in the synchronous reference frame as

$$
\frac{d}{d t}\left[\begin{array}{l}
\overline{I_{d 2}} \\
\overline{I_{q 2}}
\end{array}\right]=\left[\begin{array}{cc}
-R / L & \omega \\
-\omega & -R / L
\end{array}\right]\left[\begin{array}{l}
\overline{I_{d 2}} \\
\overline{I_{q 2}}
\end{array}\right]+\frac{\overline{V_{D C}}}{L}\left[\begin{array}{l}
d_{d} \\
d_{q}
\end{array}\right]-\frac{1}{L}\left[\begin{array}{c}
\overline{V_{d}} \\
\overline{V_{q}}
\end{array}\right]
$$

It is important to highlight that the 0 channel is no used because it is not neutral wired so this one can be omitted getting only two channels for this model.

Finally, it is possible to derive the average model of the system in DQ coordinates as shown in Figure 4 and summarized in equations (3) and (4).

$$
\begin{aligned}
& \overline{V_{D C}} d_{d}=R \overline{I_{d 2}}-\omega \overline{I_{q 2}} L+\overline{V_{d}}+L \frac{d \overline{I_{d 2}}}{d t}(3) \\
& \overline{V_{D C}} d_{q}=R \overline{I_{q 2}}+\omega \overline{I_{d 2}} L+\overline{V_{q}}+L \frac{d \overline{I_{q 2}}}{d t}(4)
\end{aligned}
$$




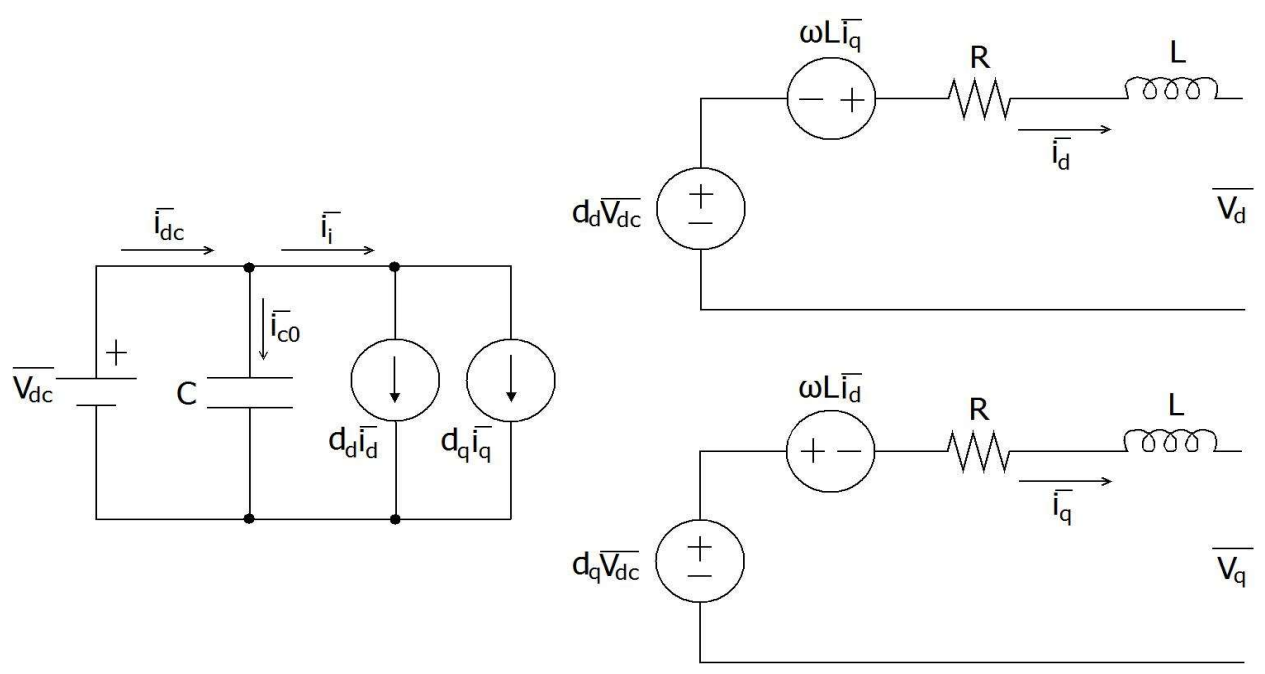

Figure 4: The average circuit in the synchronous reference frame

\subsection{Small-signal Modeling}

The next step is to obtain the small-signal model. For this purpose, a perturbation $(\widehat{\boldsymbol{d}})$ is generated around the operation point defined by the duty cycle as:

$$
\begin{aligned}
& \bar{d}=D+\hat{d}(5) \\
& \widehat{d_{d}} V_{D C}=R \widehat{I_{d 2}}-\omega \widehat{I_{q 2}} L+\widehat{V_{d}}+L \frac{d \widehat{I_{d 2}}}{d t}(6) \\
& \widehat{d_{q}} V_{D C}=R \widehat{I_{q 2}}+\omega \widehat{I_{d 2}} L+\widehat{V_{q}}+L \frac{d \widehat{I_{q 2}}}{d t}(7)
\end{aligned}
$$

By considering a stiff ac grid it is possible to neglect $\widehat{V_{d}}$ and $\widehat{V_{q}}$ in the equation (6) and (7) respectively. Therefore, a simplified model that represents the dynamic of the current can be represented as shown in Figure 5 and expressed as:

$$
\begin{aligned}
& \widehat{I_{d 2}}(s)=\frac{\widehat{d_{d}}(s) V_{D C}+\omega L \widehat{I_{q 2}}(s)}{S L+R} \\
& \widehat{I_{q 2}}(s)=\frac{\widehat{d_{q}}(s) V_{D C}-\omega L \widehat{I_{d 2}}(s)}{S L+R}
\end{aligned}
$$

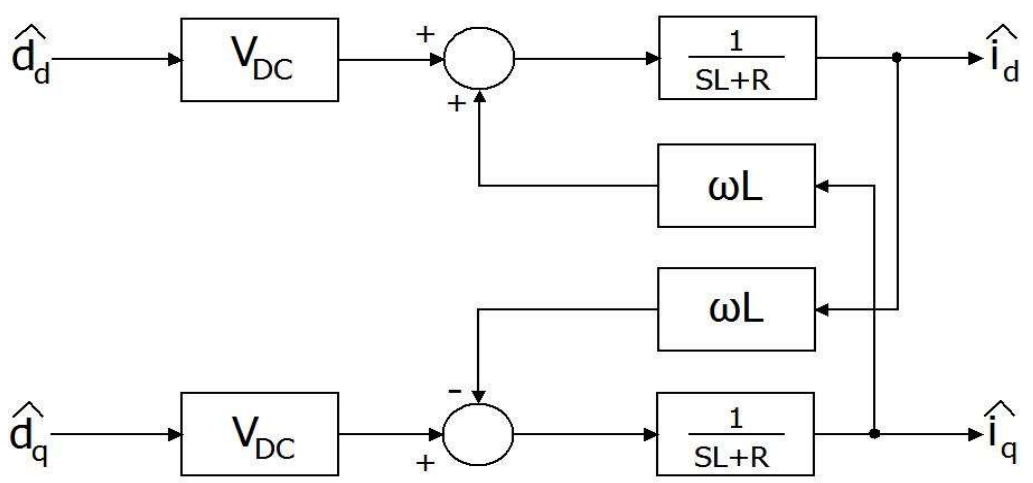

Figure 5: The small-signal model of the VSI in the stationary reference frame

As can be seen in Figure 5, there is the coupling between $\widehat{I_{d 2}}$ and $\widehat{I_{q 2}}$ through $\omega L$. To reduce the coupling effect 
and control independently every current, it is necessary to pre-compensate the model by adding the coupled variables as shown in Figure 6.

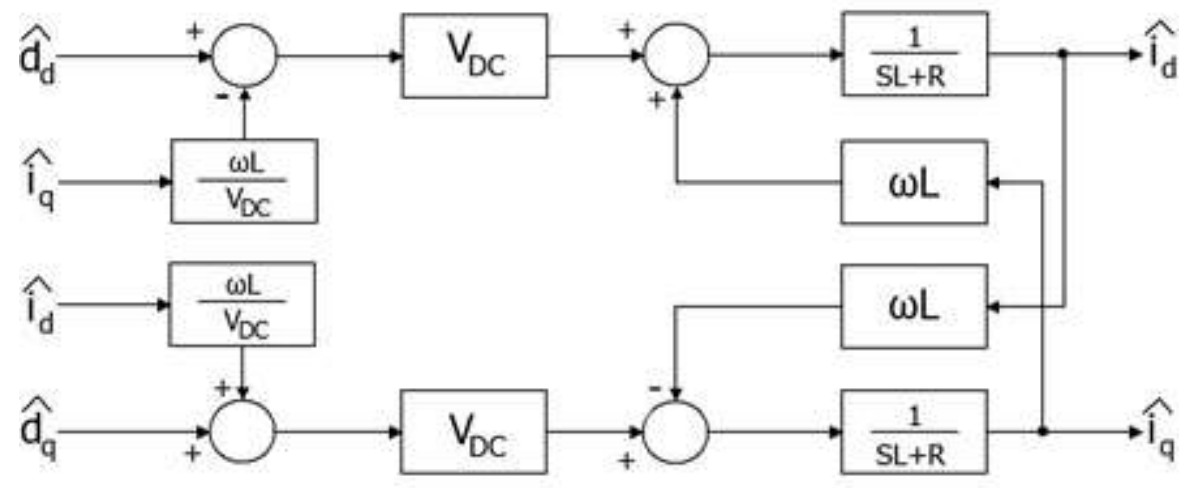

Figure 6: Small-signal model decoupled

After decoupling the DQ components, it is possible to design the PI compensator by considering the small-signal model. This one, is the same for both components, D and Q, given the symmetry of the model in which the dynamic is mainly determined by the line inductor.

$$
\frac{\hat{I}(s)}{\hat{d}(s)}=\frac{V_{D C}}{L S+R}
$$

Table 1: summarizes the main parameters of the system defined for the study case.

Table 1: Parameters of the Active Power Filter

\begin{tabular}{|l|c|}
\hline \multicolumn{1}{|c|}{ Parameter } & Value \\
\hline AC voltage & $120 / 208 \mathrm{VAC}$ \\
\hline AC frequency & $60 \mathrm{~Hz}$ \\
\hline DC voltage & $350 \mathrm{VDC}$ \\
\hline Capacitor DC bus & $2200 \mathrm{uF} 450 \mathrm{~V}$ \\
\hline Coupling inductor & $9 \mathrm{mH}$ \\
\hline Inductor resistance & $0.2 \Omega$ \\
\hline Max power & $1 \mathrm{KVA}$ \\
\hline Switching frequency & $24 \mathrm{KHz}$ \\
\hline
\end{tabular}

Then, the small-signal model can be rewritten as:

$$
\frac{\hat{I}(s)}{\widehat{d}(s)}=\frac{350}{0.009 S+0.2}(11)
$$

Whose Bode Diagram can be seen in Figure 6 


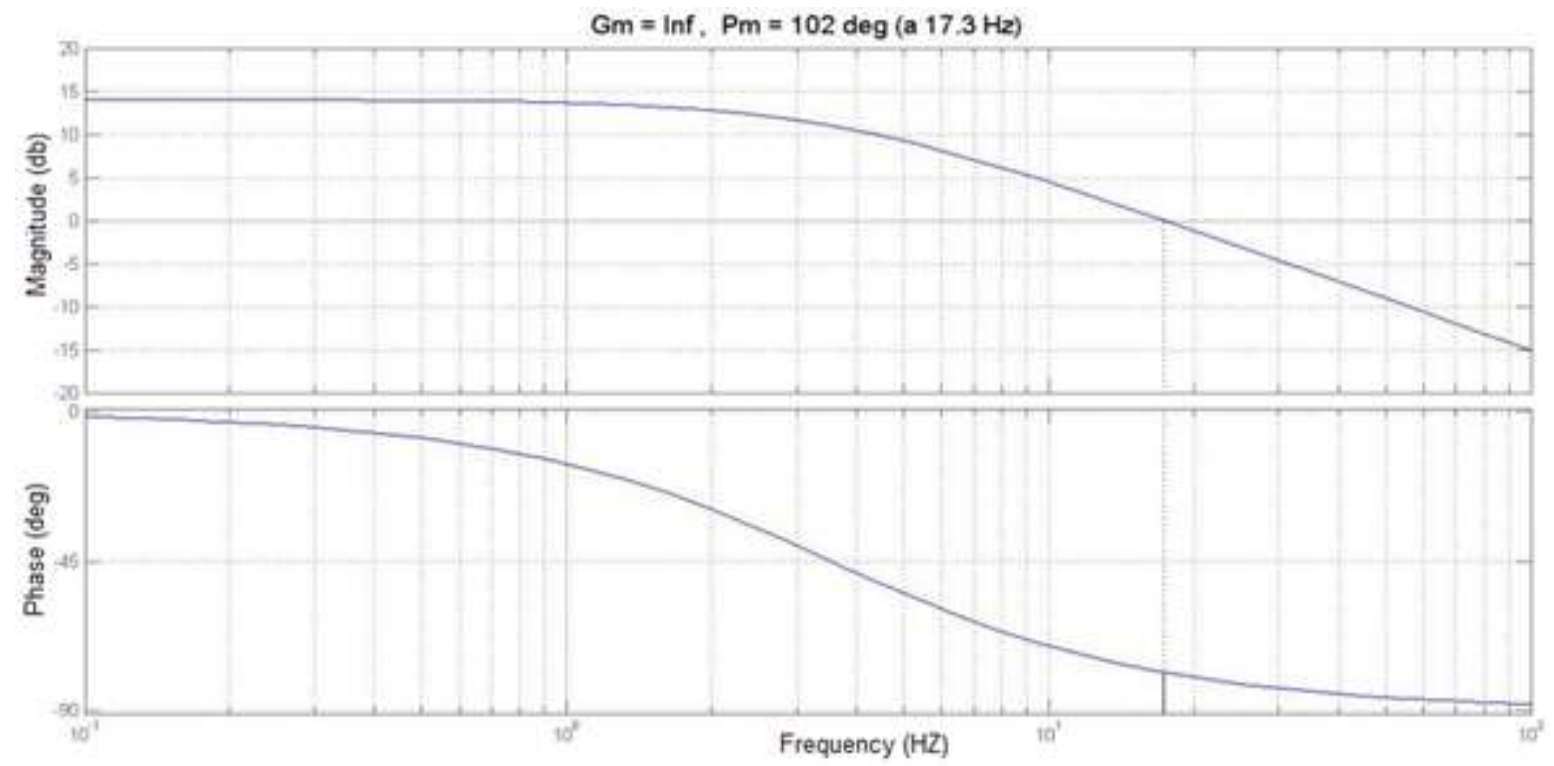

Figure 6: Bode of $I(s) / d(s)$

\subsection{PI Compensator}

This PI controller has the form of the equation (12), which is tuned based on the frequency domine response. The values of the compensator are summarized in Table II.

$$
K_{p}+\frac{K_{i}}{S}(12)
$$

Table 2. PI Compensator Values

Figure 8 shows the diagram of the compensated system in DQ reference frame whose frequency response is shown in Figure 9.

Table 2: PI compensator values

\begin{tabular}{|c|c|}
\hline Parameter & Value \\
\hline $\mathrm{Kp}$ & 226.160035 \\
\hline $\mathrm{Ki}$ & 99480.5345 \\
\hline Gain & 1 \\
\hline Margin phase & $90^{\circ}$ at $6 \mathrm{KHz}$ \\
\hline
\end{tabular}




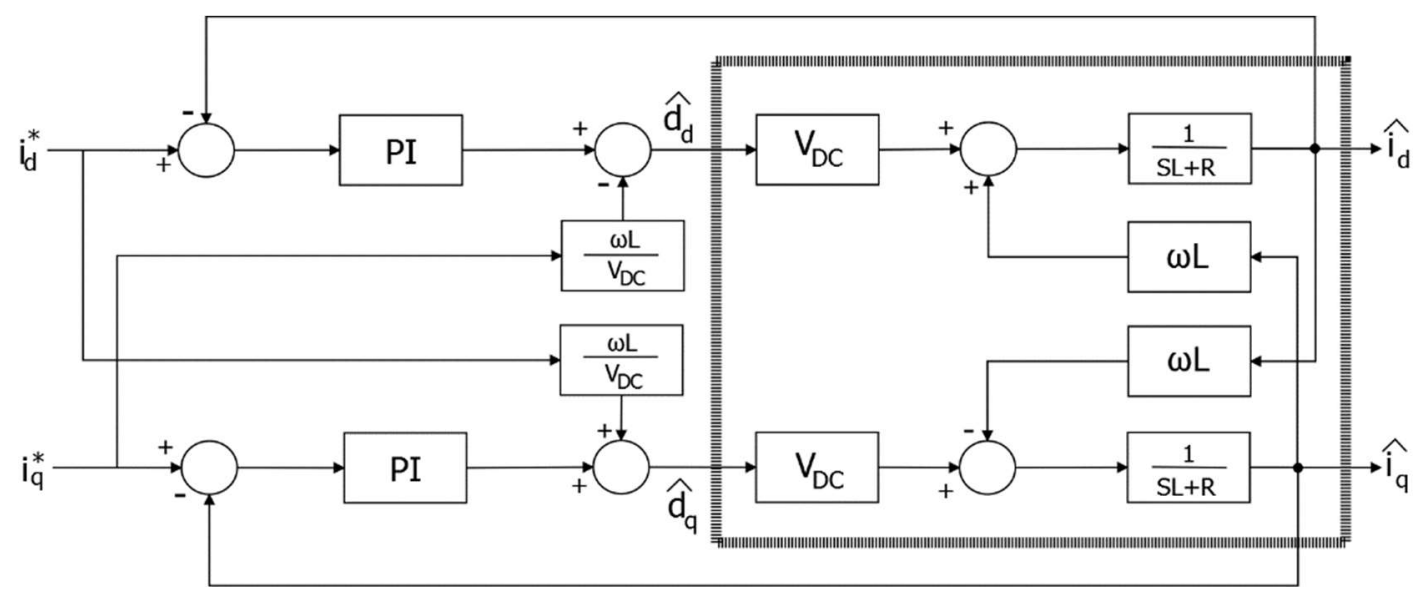

Figure 8: The control loop of the small-signal model of the VSI

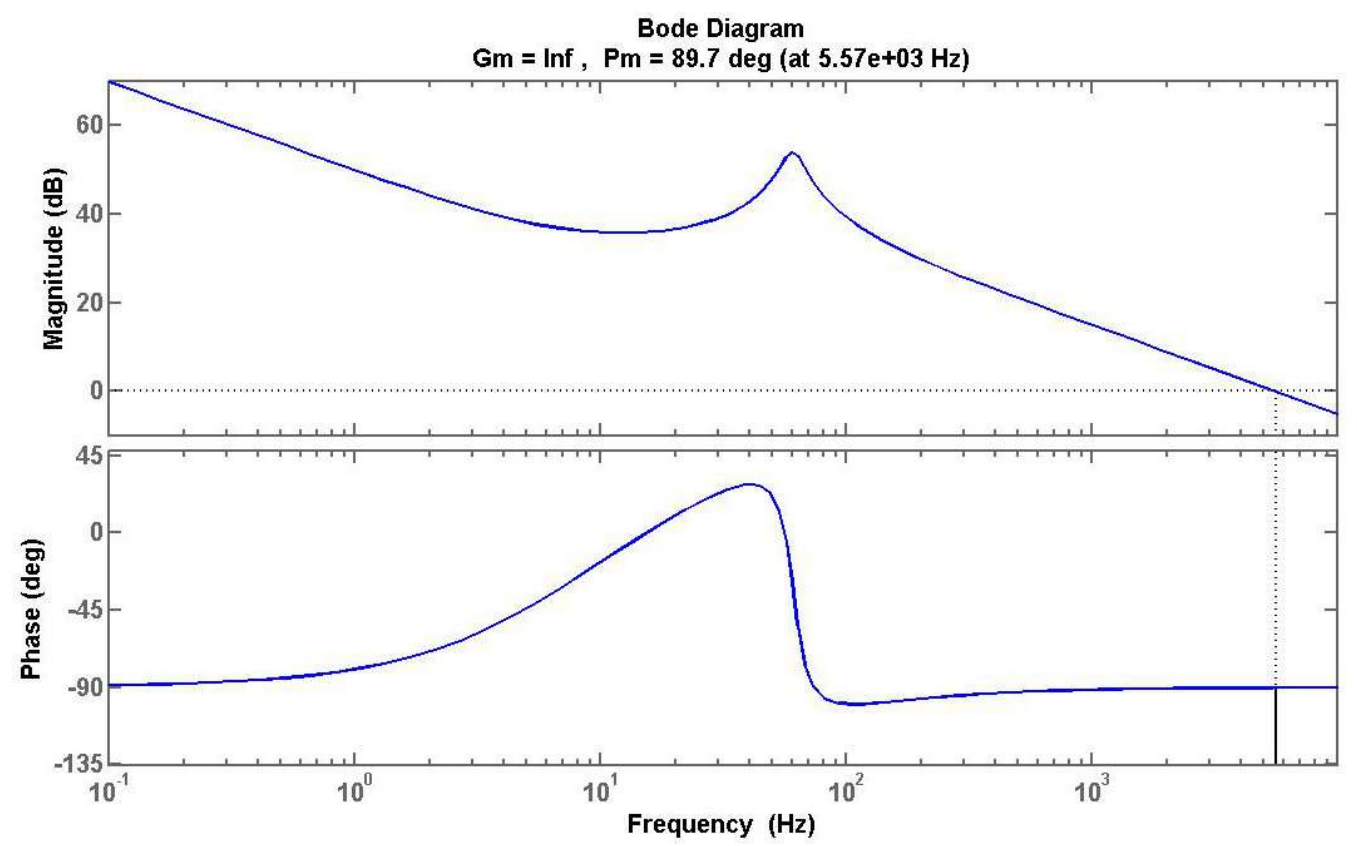

Figure 9: Bode of the small-signal model with PI compensator in open-loop

Now the challenge is to obtain the appropriate reference current that allows the compensation of the harmonic content caused by the nonlinear load.

\section{ADAPTIVE FILTER USING LMS ALGORITHM}

An adaptive filter is a system which according to the desired signal can be modified it owns parameters using a defined algorithm to reduce the error between the input signal and the reference signal [10]. As shown in Error! Reference source not found., the input signal is $d(n)$ which corresponds to the current with harmonic content (iq), and $x(n)$ represents the reference signal which is commonly a sinusoidal signal in phase with the voltage of the connection point (Vq) [11]. The output of the adaptive filter is the signal $\mathrm{y}(n)$ which should correspond to the fundamental component of the input current signal $\mathrm{d}(n)$. Therefore, the error signal $e(n)$ corresponds to the harmonic content of the current and it becomes the reference for the inner control loops $i_{q}^{*}$. Figure 11 shows the scheme of the controller integrated into the power inverter. 


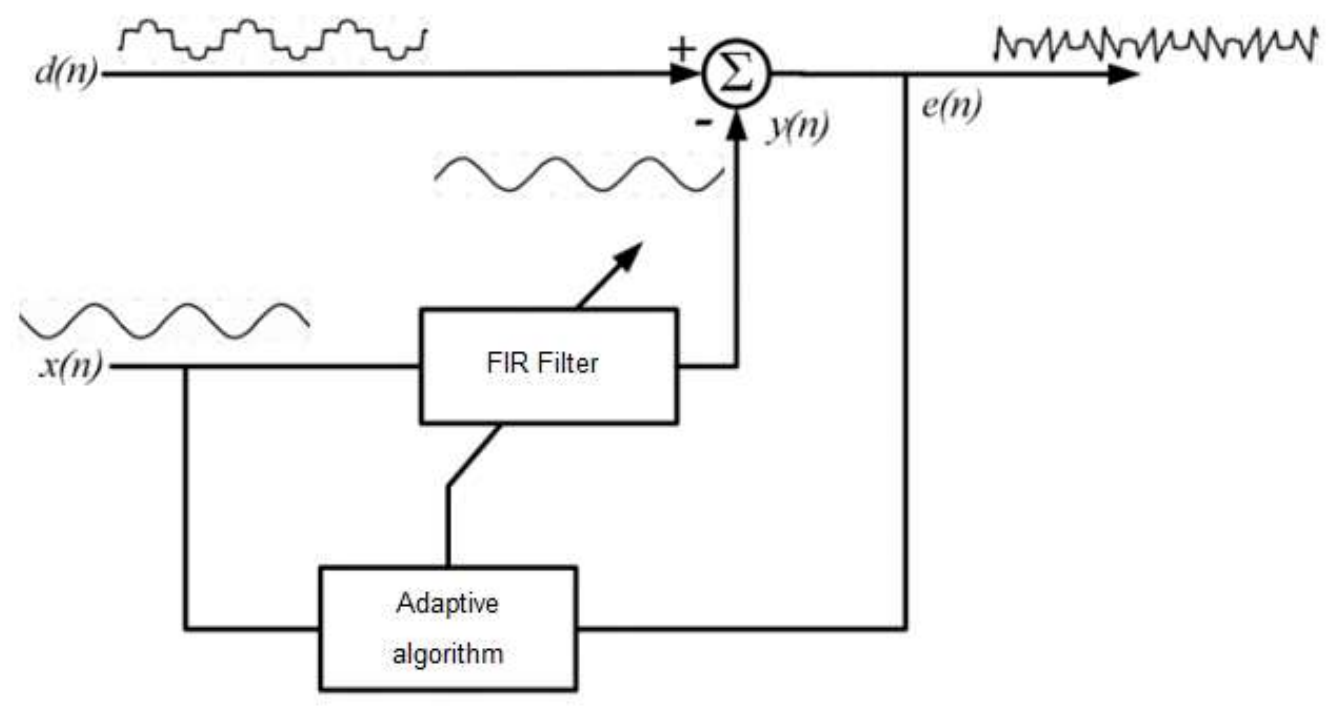

Figure 7: Scheme of an adaptive filter

Apart from that, the error $e(n)$ signal is also employed in the calculation of the new coefficients of the filter according to the LMS algorithm [12]. It is important to highlight that the design of the active filter is based on the error signal obtained from the reference voltage. Therefore, the filter will adjust its coefficients whenever a frequency variation on the grid voltage is detected.

$$
\begin{aligned}
& e(n)=d(n)-y(n) \\
& y(n)=x(n) w(n) \\
& w_{k}(n+1)=w_{k}(n)+\mu e(n) x(n-k)
\end{aligned}
$$

In (15), $\mu$ is a constant employed in the LMS algorithm to control the speed and stability of the adaptive filter. However, working in the SRF it must be considered work with the signals of the same components i.e. channel D or channel $\mathrm{Q}$, respectively.

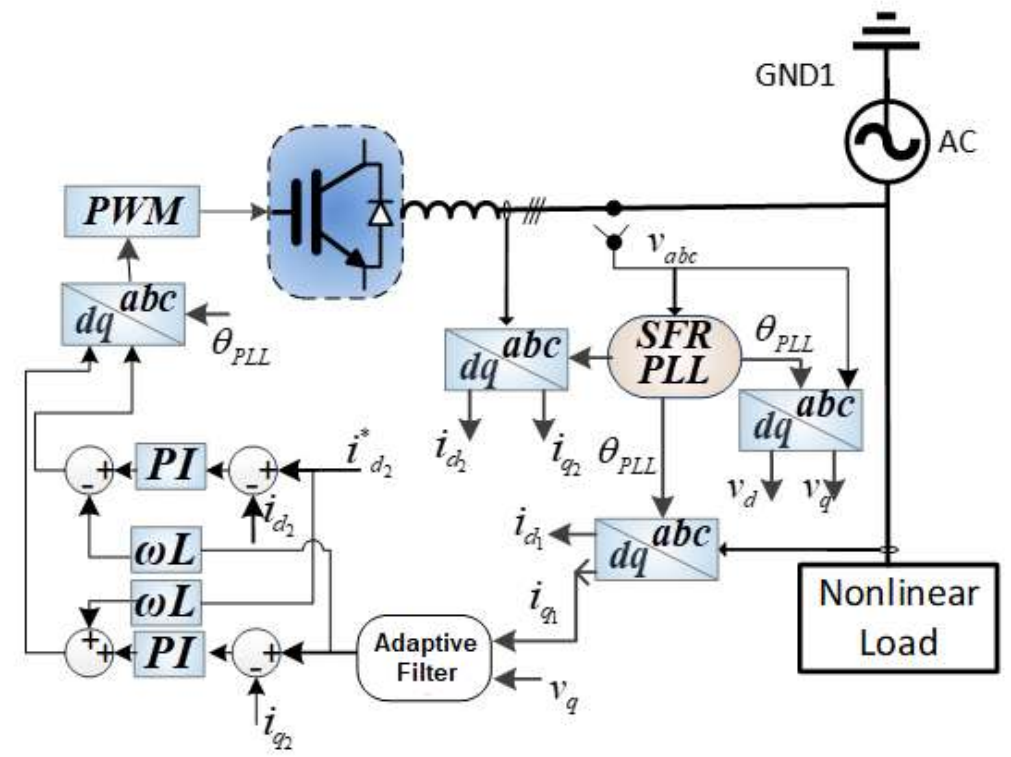

Figure 11: Scheme inverter with the controllers. 


\section{EXPERIMENTAL RESULT}

The active power filter development in this document was implemented on a DSP F28335 of Texas Instruments. This DSP was chosen due to its CPU high speed of $150 \mathrm{MHz}$, and taking advantage of his 12 PWM outputs and his 16 ADC channels. The signals of the electrical grid were taken from isolated voltage and current sensors and they were conditioned in the range of the DSP in a special board designed especially for conditioning the inputs and output signals of the controllers as shown in Figure 12.

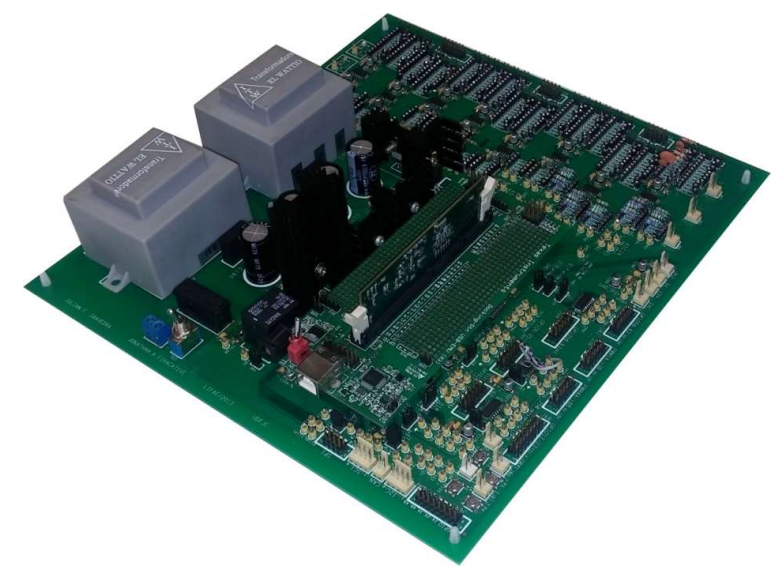

Figure 12: Designed control board.

In the first step, the algorithm implemented in the DSP acquires the signals from the grid, which are the voltage for the SRF-PLL, the currents from the non-linear load, and the currents injected by the VSI for the respective compensation. With these signals, the second step is obtaining the SRF-PLL to synchronize the injected current with the grid voltage. Then, Park's transformation is applied to the currents for obtaining the DQ components. At this point, the harmonic content of the current is obtained by employing the adaptive filter, and consequently, it is obtained the signal that is carried to the control scheme to be injected by the VSI.

The VSI and the nonlinear load were implemented in a Semitech IGBT 3M50GB123D of Semikron been the nonlinear load a three-phase full-wave rectifier of $880 \mathrm{~W}$. The main parameters of the VSI and the load are summarized in Table I. The final experimental setup is showed in Figure 13. 


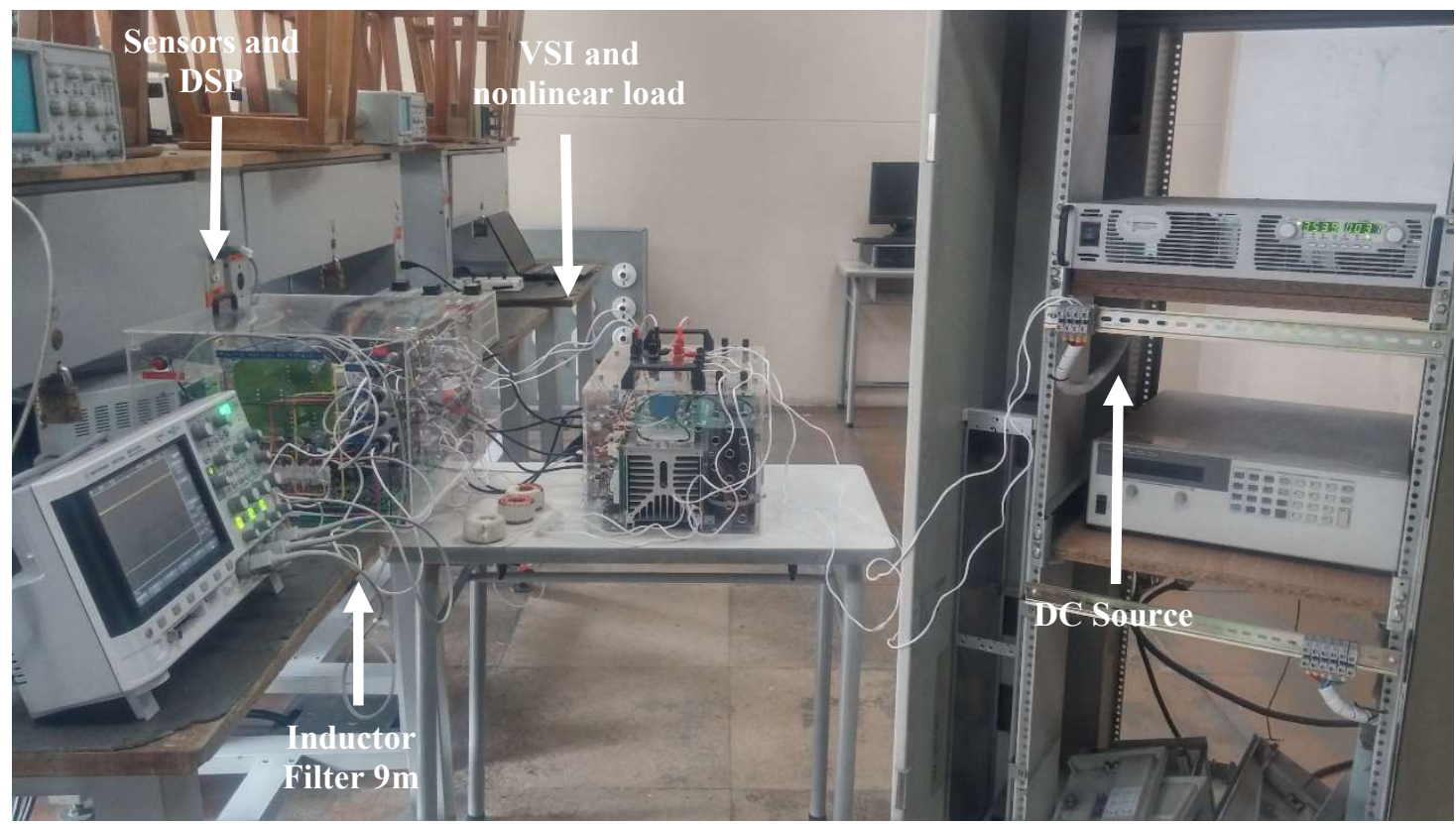

Figure 13: Experimental setup

Figure 14 shows the phase A voltage in yellow, the grid current in green, the load current in blue, and the current injected by the filter in red, before the APF operation.

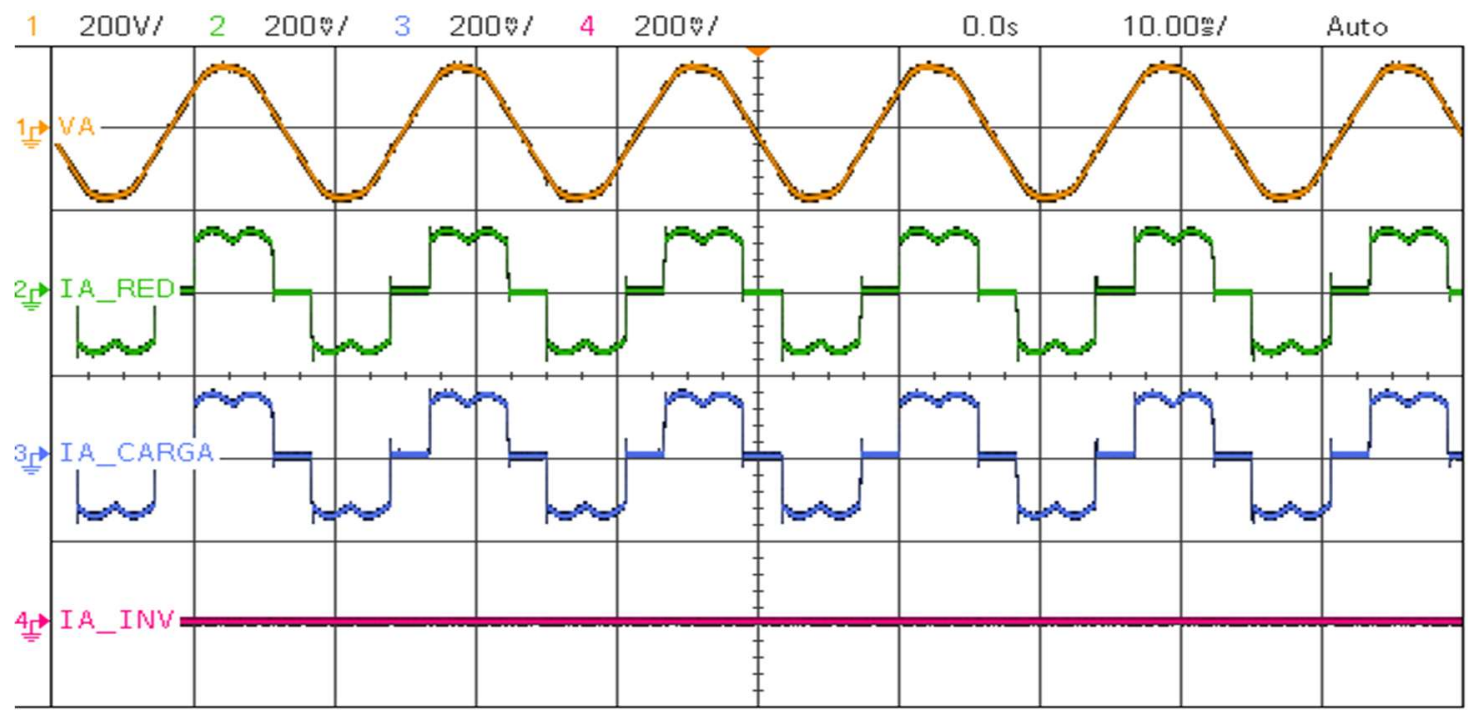

Figure 14: Voltages and currents before APF operation

As can be seen in the previous image, the grid current is equal to that of the load. The frequency of the electrical grid presents a variation between $59.9 \mathrm{~Hz}$ and $60.2 \mathrm{~Hz}$ and the THDi value for this load is $32 \%$ with a power factor of 0.71

Figure 15 shows the operation of the adaptive filter, which can modify its coefficients as a function of an error signal and the desired signal. The yellow signal represents the voltage of the electrical grid (phase A), the electrical grid current can be seen in green, in blue the current of the non-linear load, and finally in red the current injected by the filter. 


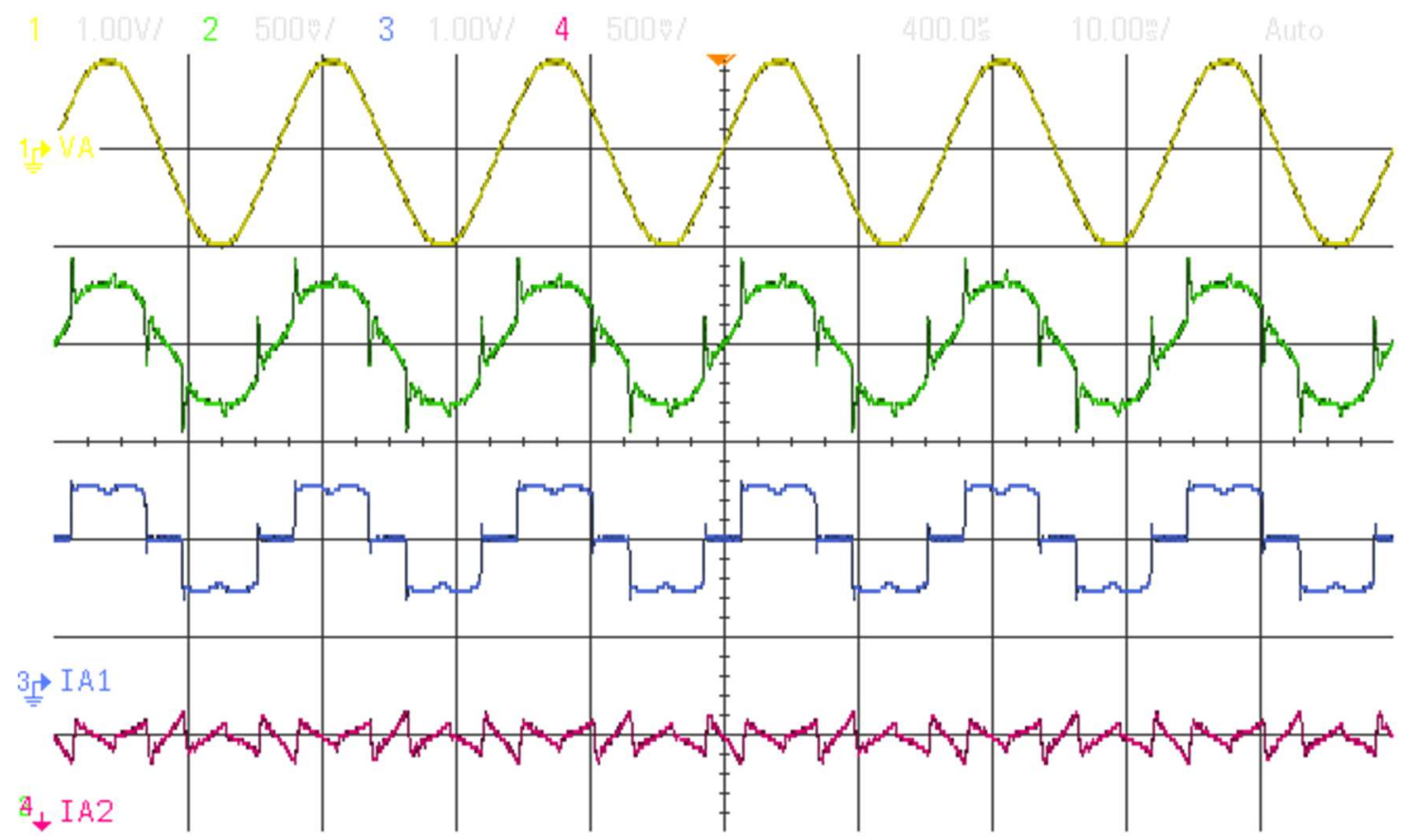

Figure 15: Waveforms with the APF operating

In the previous figure, the action of the adaptive filter can be seen, where despite the variations in frequency and the non-linearity of the load, a reduction in THDi is presented, which in this case is $9.6 \%$ with a power factor of 0.95 .

\section{CONCLUSIONS}

In this paper was presented an active power filter using adaptive filters for current harmonic mitigation. This filter consists of a VSI controlled by a DSP F28335 from Texas Instruments using the Park's transformation with the target of eliminating the stationary error on the current control loop.

The implementation of the adaptive filter significantly reduces the THDi, increases the power factor, and it is not sensitive to variations in the fundamental frequency, however, the rate of convergence of the filter is subject to a suitable selection of the $\mu$ parameter. Another advantage is that having as reference a voltage signal with which the error signal will be obtained, changes in voltage are allowed to be reflected in the behavior of the adaptive filter.

\section{REFERENCES}

1. L. Cividino, "Power factor, harmonic distortion; Causes, effects and considerations," in INTELEC, International Telecommunications Energy Conference (Proceedings), 1992.

2. J. S. Subjak and J. S. Mcquilkin, “Harmonies-Causes, Effects, Measurements, and Analysis: An Update,” IEEE Trans. Ind. Appl., 1990.

3. J. Mindykowski, T. Tarasiuk, and P. Rupnik, "Problems of passive filters application in system with varying frequency," in 2007 9th International Conference on Electrical Power Quality and Utilisation, EPQU, 2007.

4. L. Morán, J. Dixon, and M. Torres, “Active Power Filters, ” in Power Electronics Handbook, 2018.

5. B. Nayak, B. Misra, and A. Mohapatra, "A proposed reference current signal generation technique for shunt active power filter," J. Eng. Sci. Technol., 2018. 
6. J. C. Das, Power System Harmonics and Passive Filter Designs. 2015.

7. V. Vorpérian, "Simplified Analysis Of Pwm Converters Using Model Of Pwm Switch Part I: Continuous Conduction Mode," IEEE Trans. Aerosp. Electron. Syst., 1990.

8. E. Figueres, G. Garcerá, J. Sandia, F. J. González-Espin, J. Calvo, and M. Vales, "Modelling and control of a 100kW photovoltaic inverter with an LCL grid filter for distributed power systems, " in 2007 European Conference on Power Electronics and Applications, EPE, 2007.

9. E. Figueres, G. Garcerá, J. Sandia, F. González-Espin, and J. C. Rubio, "Sensitivity study of the dynamics of three-phase photovoltaic inverters with an LCL grid filter, ” in IEEE Transactions on Industrial Electronics, 2009.

10. B. Farhang-Boroujeny, Adaptive Filters: Theory and Applications, Second Edition. 2013.

11. R. R. Pereira, C. H. Da Silva, L. E. Borges Da Silva, and G. Lambert-Torres, "Application of adaptive filters in active power filters," in 2009 Brazilian Power Electronics Conference, COBEP2009, 2009.

12. J. Dhiman, S. Ahmad, and K. Gulia, “Comparison between Adaptive filter Algorithms (LMS, NLMS and RLS),” Int. J. Sci. Eng. Technol. Res., 2013. 